\title{
STUDI PENGGUNAAN BAHAN MORTAR SIKADUR-52 SEBAGAI PELINDUNG TANAH CLAY SHLAE TERHADAP PELAPUKAN
}

\author{
Julio Suryajaya $^{1}$ dan Aniek Prihatiningsih ${ }^{2}$ \\ ${ }^{1}$ Program Studi Sarjana Teknik Sipil, Universitas Tarumanagara, Jl. Letjen S. Parman No.1 Jakarta \\ Email: jsuryajaya@gmail.com \\ ${ }^{2}$ Program Studi Sarjana Teknik Sipil, Universitas Tarumanagara, Jl. Letjen S. Parman No.1 Jakarta \\ Email: aniekp@ft.untar.ac.id
}

\begin{abstract}
ABSTRAK
Penelitian ini dilatarbelakangi oleh rawannya tanah clay shale atau clay stone, mengalami pelapukan secara cepat jika terekpose udara dan air. Untuk mencegah terjadinya pelapukan, diperlukan usaha perlindungan tanah dengan cara melapisi tanah dengan bahan tambahan seperti mortar yang mudah diaplikasikan di lapangan agar tanah terlindung dari udara dan air. Penelitian dilakukan pada sampel tanah yang telah dilapisi mortar, dalam kondisi terendam air dan kondisi kering udara selama kurun waktu 1,3,5, dan 7 minggu. Setelah dilakukan pengkondisian tersebut akan dilakukan uji unconfined untuk mengetahui nilai tekan tanah dalam kondisi terlindungi. Hasil dari uji unconfined diharapkan, tidak ada perubahan pada nilai kuat tekan bebas dari masing-masing benda uji selama kurun waktu 1,3,5, dan 7 minggu. Pemilihan bahan mortar diharapkan menjadi bahan yang mudah di aplikasikan dan ekonomis, yang dapat melindungi tanah clay shale atau clay stone dari pelapukan yang disebabkan oleh udara dan air. Pada penelitian ini menunjukan bahan Sikadur-52 dapat melindungi tanah clay shale dengan cara pelapisan yang sempurna tanpa ada celah pada saat bahan dilapisi.
\end{abstract}

Kata kunci: clay shale, mortar, pelapukan, unconfined, terendam.

\section{PENDAHULUAN}

\section{Latar belakang}

Kegagalan konstruksi dinding penahan tanah pada Wisma Atlit Hambalang pada tahun 2012 dan longsornya tebing jalan tol Ungaran-Bawen pada tahun 2014 (Idrus, dkk. 2017), disebabkan oleh tidak stabilnya tanah clay shale yang terdapat pada lereng perbukitan di kedua proyek tersebut. Tanah clay shale merupakan tanah batuan yang mudah hancur atau tergdegradasi menjadi serpihan-serpihan kecil akibat proses pelapukan (weathering), yang antara lain merupakan asal-usul terbentuknya tanah ekspansif, tanah yang bermasalah di dunia konstruksi. Tanah clay shale dapat terlihat sangat keras, kaku, dan memiliki karakteristik kuat geser tanah yang tinggi, namun apabila berkontak langsung dengan air dan udara (disturbed), maka akan mengalami perubahan cepat (rapid degradation) yang menyebabkan menurunya kekuatan tanah hingga sebesar 500\% - 1000\% yang sekaligus menurunkan kuat geser tanah. Umumnya perkerjaan galian tanah untuk pembuatan lereng menyebabkan tanah clay shale mengalami kontak langsung dengan udara dan air, sehingga lereng tersebut akan mengalami kelongsoran. Pada umumnya di Indonesia banyak digunakan konstruksi batu beronjong (gabion) untuk memperbaiki kestabilan lereng. Namun demikian, apabila konstruksi batu beronjong tersebut digunakan untuk menahan tanah bersifat khusus seperti tanah clay shale maka konstruksi tersebut rawan terhadap kegagalan. Oleh karena itu, diperlukan penelitian untuk mencari alternatif lain dalam konstruksi perbaikan lereng. Dalam penelitian ini metode perlindungan dengan cara menambah lapisan baru di atas lereng untuk mencegah terjadinya kontak langsung terhadap air dan udara. Metode perlindungan lebih dipiliih karena lebih cepat diaplikasikan dan lebih murah daripada metode perbaikan pada konstruksi di lapangan. Bahan pelapis yang digunakan adalah mortar yang sering digunakan untuk melindungi dinding luar konstruksi rumah. Mortar atau disebut juga semen masonry adalah semen hidrolis, yang digunakan terutama dalam pekerjaan menembok dan memplester konstruksi, yang terdiri dari campuran dari semen portland atau campuran semen hidrolis dengan bahan yang bersifat menambah keplastisan (seperti batu kapur, kapur yang terhidrasi atau kapur hidrolis) dengan bahan lain. Penambahan bahan-bahan tersebut bertujuan untuk meningkatkan waktu pengikatan (setting time), kemampuan kerja (workability), daya simpan air (water retention), dan ketahanan (durability) (SNI 15-3758, 2004). Melapisi tanah clay shale dengan mortar diharapkan menjadi alternatif untuk memperbaiki kestabilan lereng tanah clay shale. 


\section{TINJAUAN PUSTAKA}

\section{Tanah Clay Shale}

Tanah Clay shale merupakan tanah yang tersusun dari mineral-mineral lempung yang mempunyai karakter kembang susut yang besar apabila terjadi perubahan kadar air (Anindya Yusuf, dkk. 2017). Tanah akan mengembang (swelling) pada kondisi basah dan akan menyusut (shrinkage) pada kondisi kering. Keberadaan clay shale sangat tidak stabil meskipun berada pada kontur yang datar. Tanah jenis ini memiliki kekuatan geser yang tinggi, akan tetapi kekuatan gesernya akan cepat menurun apabila berhubungan dengan atmosfer atau hidrosfer yang banyak mengandung oksigen serta hidrogen. Kekuatan geser tanah didapati menurun secara drastis apabila tanah tersebut terganggu, terpelapukan (Gartung, 1986).

Clay shale merupakan hasil pelapukan atau transportasi batuan sedimentasi tipe mekanik dengan material penyusun utamanya adalah berukuran lempung. Clay shale sendiri menjadi terkenal karena memunculkan banyak masalah geoteknik seperti kesulitan dalam memilih material timbunan, daya dukung fondasi, kestabilan lereng kontruksi bawah tanah dan lain sebagainya. Selain banyak menimbulkan masalah, para pakar kesulitan dalam pengklasifikasiannya, hal ini dikarenakan clay shale mempunyai sifat (intermediate behavior) tanah dan batuan. Clay shale sangat mudah sekali mengalami penurunan durabilitasnya dan penurunan kuat gesernya (strength degradation) apabila terekspose langsung oleh perubahan iklim, cuaca dan stress relieve, sehingga menimbulkan masalah dibidang geoteknik.

\section{Mortar}

Mortar merupakan campuran yang terdiri dari agregat (pasir), air, dan semen pada proporsi tertentu sebagai bahan perekat. Penerapan mortar lebih cenderung pada pekerjaan non-struktural seperti plesteran dinding, perekat pasangan batu bata, spesi pada fondasi batu kali, plesteran pada pemasangan keramik, batako, paving block, buis beton, roster dan sebagainya. Dilihat dari fungsinya mortar yang baik harus awet atau tahan lama, mudah di kerjakan, dan tahan terhadap unsur perusak. Manfaat mortar sebagai bahan perekat dapat menutupi atau menghilangkan permukaan yang tidak rata untuk menyalurkan beban. Fungsi dari mortar dalam plesteran untuk melindungi keawetan pasangan bata, meratakan permukaan tembok, pengikat antara pasangan bata yang satu dengan bata yang lain sehingga aksi komposit keduanya dapat terbentuk. Fungsi utama mortar yaitu menambal rekatan dan durabilitas ikatan dengan bagian-bagian penyusun suatu konstruksi. Pada penelitian ini akan digunakan bahan mortar Sikadur-52.

Tabel 1 Perbandingan Bahan Sikadur-52 Dengan Bahan Lainya

Sikadur-52

\begin{tabular}{lc}
\hline Compresive Strength & $44 \mathrm{mPa}$ \\
\hline Tensile Strenght & $22 \mathrm{mPa}$
\end{tabular}

SikaTop-107 Plus

\begin{tabular}{lc}
\hline Compresive Strength & $30 \mathrm{mPa}$ \\
\hline Tensile Strenght & $20 \mathrm{mPa}$
\end{tabular}

\section{Unconfined Compression Test (UCT)}

Pada material tanah, parameter yang perlu ditinjau adalah kuat geser tanah. Kuat geser tanah adalah gaya perlawanan yang dilakukan oleh butir-butir tanah terhadap desakan atau tarikan (Hardiyatmo, 2002). Salah satu pengujian yang digunakan untuk mengetahui parameter kuat geser tanah ialah uji kuat tekan bebas. Kuat tekan bebas adalah besar beban aksial persatuan luas saat benda uji mengalami keruntuhan atau pada saat regangan aksial (ع) mencapai 15\% (ASTM D2166/D2166M-13).

Tegangan aksial $\left(\sigma_{1}\right)$ yang diterapkan pada benda uji berangsur-angsur ditambah sampai benda uji mengalami keruntuhan. Pada saat keruntuhan, karena tegangan lateralnya nol $\left(\sigma_{3}=0\right)$ maka didapat persamaan sebagai berikut:

Keterangan:

$$
\sigma_{1}=\sigma_{3}+\Delta \sigma_{\mathrm{f}}=\Delta \sigma_{\mathrm{f}}=\mathrm{qu}
$$

$\mathrm{q}_{\mathrm{u}}=$ kuat tekan bebas (unconfined compressive strength).

Beberapa persamaan untuk mendapatkan nilai kuat tekan bebas, antara lain:

1. Regangan aksial $(\varepsilon)$

$$
\varepsilon \frac{\Delta \mathrm{L}}{\mathrm{LO}} \quad \mathrm{x} 100 \%
$$




\section{Keterangan:}

$\Delta \mathrm{L}=$ perubahan panjang benda uji

Lo $=$ panjang benda uji mula-mula .

2. Luas penampang benda uji selama pembebanan (Ac)

$$
\mathrm{Ac}=\frac{\text { Ao }}{1-\varepsilon}
$$

Keterangan:

Ao = luas penampang benda uji mula-mula

$\varepsilon=$ regangan aksial.

3. Tegangan aksial $(\sigma)$

$$
\sigma=\frac{\mathrm{P}}{\mathrm{Ac}}
$$

Keterangan:

$\mathrm{P}=$ beban yang bekerja.

Pembuatan kurva tegangan-regangan dengan menghubungkan data regangan aksial pada sumbu absis, dan tegangan aksial pada sumbu ordinat. Kuat tekan aksial ditentukan berdasarkan nilai tegangan aksial maksimum, $q_{u}=\sigma_{\max }$. Sedangkan regangan yang dicapai saat tegangan aksial maksimum merupakan regangan runtuh.

Untuk mendapatkan kuat geser tanah, dapat diperhitungkan dari kuar tekan bebas yang didapat. Setengah dari nilai kuat tekan bebas merupakan kuat geser tanah tersebut.

$\mathrm{S}_{\mathrm{u}}=\mathrm{q}_{\mathrm{u}} / 2$

Keterangan:

$\mathrm{S}_{\mathrm{u}}=$ Kuat geser tanah.

$\mathrm{q}_{\mathrm{u}}=$ Kuat tekan bebas tanah (unconfined compressive strength)

\section{METODOLOGI PENELITIAN}

\section{Pengambilan Tanah}

Pengambilan benda uji tanah dari lokasi Jalan Babakan Sirkuit Tangkil Citureup Bogor, Jawa Barat. Benda uji tanah diperoleh dari hasil galian basement kemudian tanah segera dimasukan ke dalam karung lalu dimasukan kembali ke dalam poly bag hitam dan direkatkan dengan selotip agar tidak terlalu lama mengalami kontak dengan udara. Setelah itu benda uji tanah dibawa ke laboratorium Mekanika Tanah Universitas Tarumanagara. Tanah yang diambil merupakan tanah disturbed atau tanah terganggu, karena telah terpapar udara terbuka sehingga memiliki kadar air berbeda dengan kadar air tanah insitu. Berikut merupakan gambar tanah clay shale yang diambil sebanyak dua kontainer.

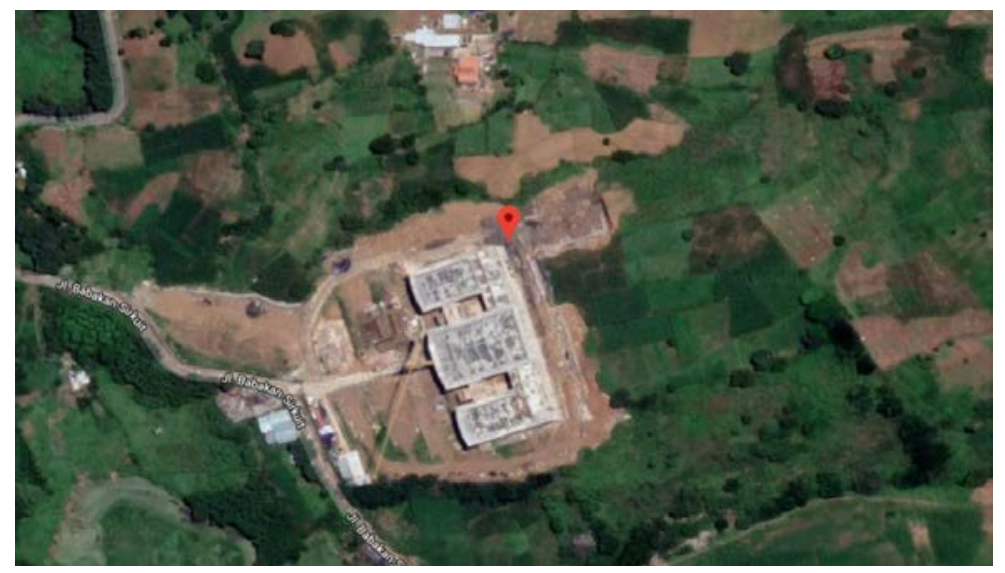

Gambar 1 Lokasi Pengambilan Tanah dari Satelit 


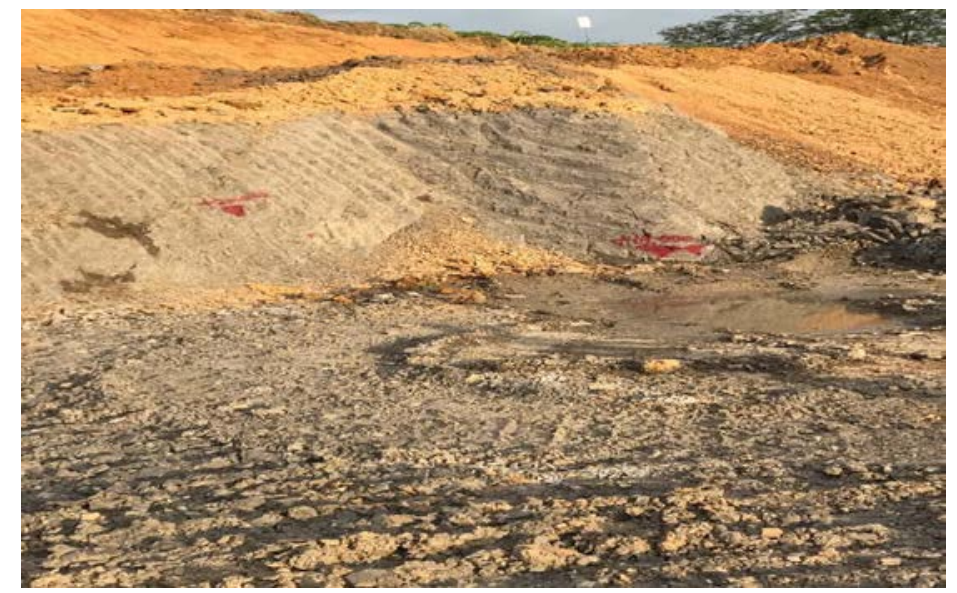

Gambar 2 Tanah Clay Shale yang terdapat pada Proyek di Jalan Babakan Sirkuit Tangkil Citureup Bogor,

Jawa Barat.

\section{Uji Karakteristik Tanah}

Pengujian karakteristik tanah yang akan dilakukan menggunakan pedoman ASTM (American Society for Testing and Materials), 5 pengujian karakteristik tanah dan pengujian unconfined compression test (UCT) tersebut antara lain:
1. Water content
2. Specific gravity
$=$ ASTM D 2216
= ASTM D 854
3. Atterberg limits
= ASTM D 4318
4. Sieve analysis
= ASTM D 422
5. Hydrometer analysis
= ASTM D 422
6. Compaction
= ASTM D 698
7. Unconfined compression test = ASTM D 2166.

\section{Pembuatan Sampel dan Pelapisan Bahan Sikadur-52}

Persiapan sampel diawali dengan menyaring tanah clay shale dengan saringan no.10. Pemakaian saringan no.10 (2,00 mm) ini berdasarkan ASTM D2166-13 yang mengatakan bahwa sampel UCT dengan diameter minimal 30 mm tersusun atas butiran-butiran tanah yang memiliki ukuran lebih kecil dari sepersepuluh (1/10) diameter sampel, sedangkan sampel UCT dengan diameter $72 \mathrm{~mm}$ atau lebih besar memiliki ukuran butiran terbesar lebih kecil dari seperenam (1/6) diameter sampel. Rata-rata diameter sampel yang digunakan pada pengujian ini adalah $38 \mathrm{~mm}$, sehingga ukuran butiran terbesar yang terkandung dalam sampel yaitu 3,8 mm. Jadi digunakan saringan no.10 (2,00 $\mathrm{mm})$. Setelah proses penyaringan, tanah dicampur dengan air hingga mencapai kadar air optimum. Proses pencampuran air harus dilakukan secara merata, tidak diperkenankan adanya gumpalan tanah karena gumpalan tanah tersebut mengikat sejumlah air. Proses selanjutnya ialah pembuatan sampel UCT.

Proses pembuatan sampel dimulai dari perhitungan berat tanah yang akan dimasukkan ke dalam mold UCT berdasarkan ukuran volume mold UCT, kadar air optimum, dan kepadatan kering tanah maksimum $\left(\gamma_{\text {dmax }}\right)$. Setelah mendapatkan berat tanah yang akan dimasukkan kedalam mold UCT dilakukan proses pemadatan dengan tujuan mold UCT terisi penuh tanpa kekurangan ataupun kelebihan tanah. Upaya yang dilakukan adalah tanah yang dimasukkan ke mold dibagi rata menjadi 3 lapisan, tiap lapisan memiliki ketebalan dan berat yang sama. Penumbukan tanah dilakukan agar tiap lapisan memiliki ketebalan yang sama, dan dikontrol dengan alat bantu yang dapat mengukur ketebalan berupa kayu yang telah diberi tanda. Sebelum tanah dimasukkan kedalam mold, mold dilumasi dengan pelumas untuk meminimalisasi gaya gesek ketika proses pengeluaran sampel tanah dari mold. Lapisan pelindung dengan bahan mortar yang digunakan, memiliki ketebelan maksimum 2 mm. Jika ketebalan lapisan mortar melebihi 2 mm, maka kekuatan bahan mortar akan menggangu nilai tekan bebas dari hasil uji UCT. Proses pengaplikasian mortar dilakukan setelah mencampur bahan resin dan bahan pengeras dengan perbandingan 2 : 1 dan bahan pewarna resin yang berwarna biru muda. Penambahan pewarna bertujuan untuk membedakan lapisan tanah yang berwarna abu-abu dan lapisan mortar yang berwarna biru muda. Bahan mortar diaduk dengan menggunakan mixer dengan kecepatan tinggi agar tercampur dengan rata. Bahan mortar cair kemudian dioleskan dengan kuas secara merata di permukan benda uji, pelapisan dilakukan 3 kali dengan rentan 30, 60 , dan 90 menit. Jika pelapisan dilakukan pada rentan waktu terlalu lama maka cairan mortar akan lebih kental dan lengket, sehinnga 
lebih sulit untuk melapisi benda uji. Pada bagian bawah dan atas benda uji diberi kertas pori agar air tidak masuk melawati sudut-sudut permukaan benda uji. Setelah proses pelapisan selesai maka selanjutnya benda uji akan melalui proses pengkondisian kering udara dan perendaman selama durasi waktu 1,3,5, dan 7 minggu.

\section{Unconfined Compression Test (UCT)}

Setelah proses pengkondisian maka masing-masing benda uji akan melalui uji UCT untuk mengetahui adakah perubahan setelah dilakukan proses kering udara dan perendaman terhadap nilai kuat tegangan gesernya. Nilai kuat geser dari setiap benda uji akan menjadi faktor pembanding untuk mengetahui kemampuan bahan Sikadur-52 dalam melindungi tanah clay shale.

\section{ANALISIS DAN PEMBAHASAN}

\section{Hasil Uji Klasifikasi Tanah}

Tabel 2 Hasil Uji Klasifikasi Tanah

\begin{tabular}{lc}
\hline Lokasi & Citeureup \\
\hline Specific gravity $\left(\mathrm{G}_{\mathrm{s}}\right)$ & 2,75 \\
\hline Presentase kerikil(\%) & 0,00 \\
\hline Presentase pasir (\%) & 1,74 \\
\hline Presentase lanau (\%) & 85,14 \\
\hline Presentase lempung (\%) & 13,13 \\
\hline Liquid Limit (LL) & 34 \\
\hline Plastic Limit (PL) & 26,6 \\
\hline Plasticity Index (PI) & 7,2 \\
\hline Klasifikasi ASTM & Lanau (ML) \\
\hline
\end{tabular}

\section{Analisa Hasil Uji UCT}

Pada bagian ini akan dibandingkan perbedaan nilai kuat tekan bebas sampel uji tanah clay shale yang telah dilapisi bahan Sikadur-52, pada kondisi tidak direndam air dan direndam air dengan durasi yang berbeda-beda. Perbandingan dilakukan pada nilai kuat tekan bebas maksimum seluruh sampel di setiap durasi.Nilai kuat tekan bebas maksimum tersebut diaplikasikan menjadi suatu grafik yang dapat memudahkan proses analisa pengaruh durasi terhadap nilai kuat tekan bebas tanah.

\section{Nilai Kuat Tekan Bebas Pada Benda Uji Tidak Direndam}

Pertama-tama, akan dianalisa benda uji yang tidak direndam terlebih dahulu, berikut merupakan tabel kuat tekan bebas maksimum benda uji tidak direndam dari seluruh benda uji disetiap durasi:

Tabel 3 Nilai Tegangan Maksimum Pada Benda Uji Tidak Direndam

\begin{tabular}{ccccc}
\hline 0 Hari & Benda Uji 1 & Benda Uji 2 & Benda Uji 3 & Benda Uji 4 \\
\hline Quu (kPa) & 446,0607 & 468,5256 & 453,8106 & 443,1177 \\
\hline 1 Minggu & Benda Uji 1 & Benda Uji 2 & Benda Uji 3 & Benda Uji 4 \\
\hline Quu (kPa) & 549,36 & 629,7039 & 422,7129 & 802,8504 \\
\hline 3 Minggu & Benda Uji 1 & Benda Uji 2 & Benda Uji 3 & Benda Uji 4 \\
\hline Quu (kPa) & 661,35096 & 580,31055 & 927,62379 & 1063,0116 \\
\hline 5 Minggu & Benda Uji 1 & Benda Uji 2 & Benda Uji 3 & Benda Uji 4 \\
\hline Quu (kPa) & 1026,9108 & 1016,4141 & 0 & 0 \\
\hline 7 Minggu & Benda Uji 1 & Benda Uji 2 & Benda Uji 3 & Benda Uji 4 \\
\hline Quu (kPa) & 531,8001 & 389,5551 & 516,5946 & 516,7908 \\
\hline
\end{tabular}




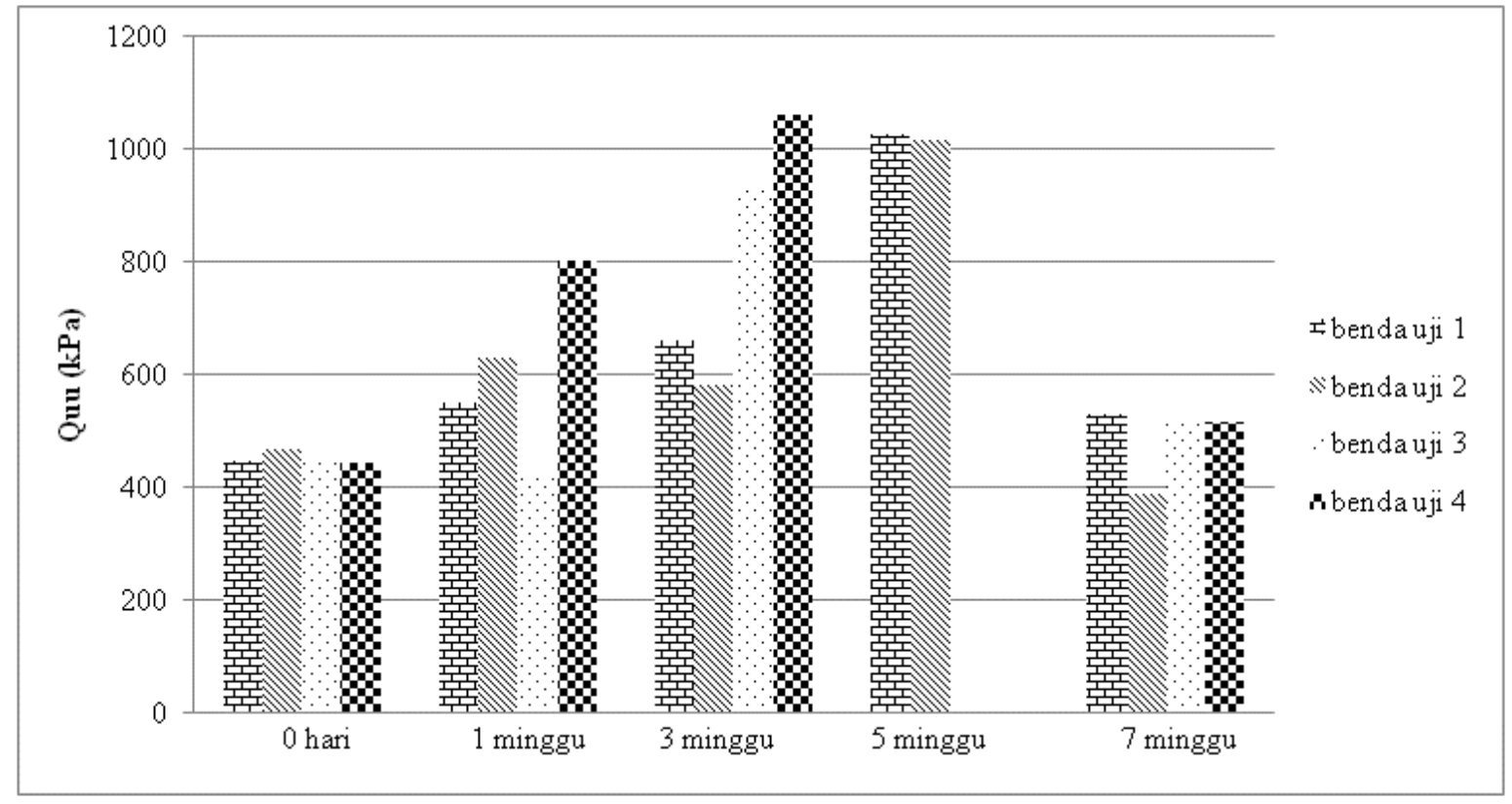

Gambar 3 Grafik Distribusi Nilai Kuat Tekan Maksimum Pada Benda Uji Tidak Direndam

Dilihat dari grafik pada Gambar 3 nilai kuat tekan menunjukan variasi pada setiap benda uji. Hal ini terjadi dikarenakan, perbedaan ketebalan lapisan dan lubang kecil pada permukaan lapisan yang menyebabkan menguapnya air sehingga terjadi penurunan berat benda uji. Semakin besar penurunan berat benda uji maka semakin tinggi nilai kuat tekan. Perbedaan berat dapat dilihat pada Tabel 4.

Tabel 4 Selisih Berat Pada Setiap Benda Uji Tidak Direndam

\begin{tabular}{ccccc}
\hline 0 Hari & Benda Uji 1 & Benda Uji 2 & Benda Uji 3 & Benda Uji 4 \\
\hline Selisih Berat (gram) & 0 & 0 & 0 & 0 \\
\hline 1 Minggu & Benda Uji 1 & Benda Uji 2 & Benda Uji 3 & Benda Uji 4 \\
\hline Selisih Berat (gram) & $-0,9$ & $-0,8$ & $-1,1$ & -6 \\
\hline 3 Minggu & Benda Uji 1 & Benda Uji 2 & Benda Uji 3 & Benda Uji 4 \\
\hline Selisih Berat (gram) & $-0,7$ & $-2,6$ & $-10,1$ & $-7,5$ \\
\hline 5 Minggu & Benda Uji 1 & Benda Uji 2 & Benda Uji 3 & Benda Uji 4 \\
\hline Selisih Berat (gram) & $-5,8$ & -3 & & Benda Uji 4 \\
\hline 7 Minggu & Benda Uji 1 & Benda Uji 2 & Benda Uji 3 & -1 \\
\hline Selisih Berat (gram) & $-1,5$ & $-1,6$ & $-1,5$ &
\end{tabular}

\section{Nilai Kuat Tekan Bebas Pada Benda Uji Direndam}

Sama seperti benda uji tanah yang tidak direndam, analisa dilakukan pada nilai kuat tekan bebas maksimum dari seluruh benda uji tanah yang direndam disetiap durasi. Berikut merupakan tabel kuat tekan bebas maksimum benda uji direndam: 
Tabel 5 Nilai Tegangan Maksimum Pada Benda Uji Direndam

\begin{tabular}{ccccc}
\hline 0 Hari & Benda Uji 1 & Benda Uji 2 & Benda Uji 3 & Benda Uji 4 \\
\hline Quu (kPa) & 446,0607 & 468,5256 & 453,8455255 & 443,1524953 \\
\hline 1 Minggu & Benda Uji 1 & Benda Uji 2 & Benda Uji 3 & Benda Uji 4 \\
\hline Quu (kPa) & 349,25562 & 391,1247 & 0 & 0 \\
\hline 3 Minggu & Benda Uji 1 & Benda Uji 2 & Benda Uji 3 & Benda Uji 4 \\
\hline Quu (kPa) & 533,3697 & 478,5318 & 465,22944 & 349,6284 \\
\hline 5 Minggu & Benda Uji 1 & Benda Uji 2 & Benda Uji 3 & Benda Uji 4 \\
\hline Quu (kPa) & 590,6601 & 534,9393 & 0 & 0 \\
\hline 7 Minggu & Benda Uji 1 & Benda Uji 2 & Benda Uji 3 & Benda Uji 4 \\
\hline Quu (kPa) & 169,4187 & 104,2803 & 0 & 0 \\
\hline
\end{tabular}

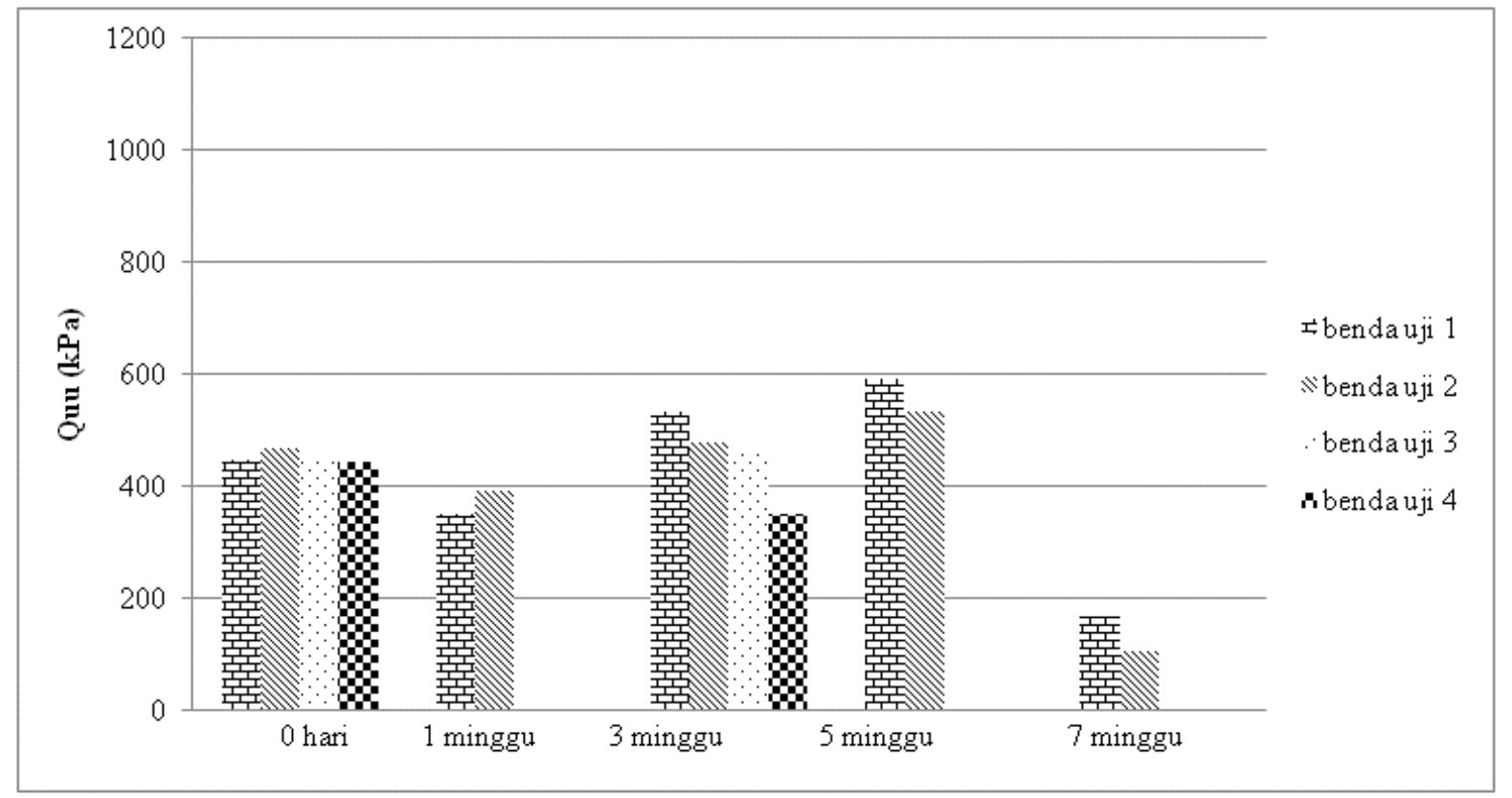

Gambar 4 Grafik Distribusi Nilai Kuat Tekan Maksimum Pada Benda Uji Direndam

Dilihat dari grafik pada Gambar 4, nilai kuat tekan dari durasi 0 hari, 1, 3, dan 5 minggu tidak memiliki perbedaan yang terlalu besar. Tetapi pada durasi 7 minggu, nilai kuat tekan mengalami penurunan. Hal tersebut terjadi karena adanya air yang masuk lewat lubang atau celah pada permukaan lapisan pelindung sehingga bertambahnya berat benda uji. Perbedaan berat dapat dilihat pada Tabel 5. 
Tabel 6 Selisih Berat Pada Setiap Benda Uji Direndam

\begin{tabular}{ccccc}
\hline 0 Hari & Benda Uji 1 & Benda Uji 2 & Benda Uji 3 & Benda Uji 4 \\
\hline Selisih Berat (gram) & 0 & 0 & 0 & 0 \\
\hline 1 Minggu & Benda Uji 1 & Benda Uji 2 & Benda Uji 3 & Benda Uji 4 \\
\hline Selisih Berat (gram) & 0,2 & 2,5 & 0 & 0 \\
\hline 3 Minggu & Benda Uji 1 & Benda Uji 2 & Benda Uji 3 & Benda Uji 4 \\
\hline Selisih Berat (gram) & 1,2 & 1,8 & 2,6 & 1,8 \\
\hline 5 Minggu & Benda Uji 1 & Benda Uji 2 & Benda Uji 3 & Benda Uji 4 \\
\hline Selisih Berat (gram) & 1 & 1,4 & & Benda Uji 4 \\
\hline 7 Minggu & Benda Uji 1 & Benda Uji 2 & Benda Uji 3 & \\
\hline Selisih Berat (gram) & 7,7 & 8,8 & & \\
\hline
\end{tabular}

\section{KESIMPULAN}

1. Pada kondisi kering udara, benda uji memliki nilai tekan yang tinggi tetapi nilai regangan yang rendah. Sebaliknya pada kondisi terendam, benda uji memiliki nilai tekan yang rendah tetapi nilai rengangan yang tinggi.

2. Penelitian ini menunjukan, bahan Sikadur-52 dapat melindungi benda uji tanah clay shale mengalami kontak dengan air. Hal ini dibuktikan dengan tidak terjadinya perubahan nilai tekan pada benda uji yang terlindung sempurna selama durasi 0 hari, 1, 3, dan 5 minggu pada kondisi direnadam air.

3. Pada uji UCT ditemukan variasi nilai tekan, hal ini terjadi karena sulitnya mencegah benda uji mengalami kontak dengan air dan udara. Lapisan bahan Sikadur-52 harus merata secara sempurna tanpa ada celah atau retakan sedikitpun, untuk mencegah kontak dengan air dan udara.

\section{DAFTAR PUSTAKA}

Gartung, E. 1986. Excavation of The Hard Clays of The Keuper Formation Proceeding of Symposium Geotechnical Engineering Divission. Seatle. Washington.

Hardiyatmo, H.C. 2002. Mekanika Tanah 1. Gadjah Mada University Press, Yogyakarta.

Idrus M Alatas, Pintor T. Simatupang. 2017. Pengaruh Proses Pelapukan Clay Shale Terhadap Perubahan Parameter Rasio Disintegritas (DR). Universitas Mercu Buana. 